\title{
Clinical and nutritional correlations in Parkinson's disease: Preliminary report
}

\author{
Sławomir Budrewicz ${ }^{1, A, E, F}$, Anna Zmarzły 2,B, Dominik Rączka2,B, Aleksandra Szczepańska ${ }^{1, C}$, \\ Ewa Koziorowska-Gawron ${ }^{1, B, D}$, Krzysztof Słotwiński ${ }^{1}, C_{1}$, , Magdalena Koszewicz ${ }^{1, D-F}$ \\ ${ }^{1}$ Department of Neurology, Wroclaw Medical University, Poland \\ ${ }^{2}$ Clinical Nutrition Unit, J. Gromkowski Regional Specialist Hospital, Wrocław, Poland \\ A - research concept and design; $\mathrm{B}$ - collection and/or assembly of data; $\mathrm{C}$ - data analysis and interpretation; \\ $\mathrm{D}$ - writing the article; $\mathrm{E}$ - critical revision of the article; $\mathrm{F}$ - final approval of the article
}

Address for correspondence

Magdalena Koszewicz

E-mail:magdalena.koszewicz@umed.wroc.pl

Funding sources

None declared

Conflict of interest

None declared

Received on July 19, 2017

Reviewed on July 24, 2017

Accepted on August 11, 2017

Published online on July 2, 2018

Cite as

BudrewiczS, Zmarzły A, Rączka D, et al. Clinical and nutritional correlations in Parkinson's disease: Preliminary report. Adv Clin Exp Med. 2019;28(2):193-198. doi:10.17219/acem/76375

DOI

10.17219/acem/76375

Copyright

Copyright by Author(s)

This is an article distributed under the terms of the

Creative Commons Attribution Non-Commercial License

(http://creativecommons.org/licenses/by-nc-nd/4.0/)

\section{Abstract}

Background. Parkinson's disease (PD) is one of the most common neurodegenerative disorders. Malnutrition is an essential problem in the late stage of PD. Lowering of body mass is seen in 30\% of patients, and malnutrition or the risk of malnutrition in $24 \%$ and $60 \%$, respectively.

Objectives. The aim of the study was an analysis of the relationships between the parameters of the nutritional stage and the advancement of clinical symptoms in PD patients.

Material and methods. A total of 40 patients (18 men, 22 women) with PD were analyzed, mean age: 70.7 years. In all patients, structured anamnesis, Nutrition Risk Screening (NRS 2002), body mass index (BMI), morphology, and basic biochemical tests were conducted. Skin fold thickness was also measured. The results were referred to the score of different scales.

Results. The study showed a lot of correlations between the severity of PD, mostly motor symptoms in the Unified Parkinson's Disease Rating Scale (UPDRS), and parameters characterizing the patient's nutritional status. We revealed a correlation between malnutrition and PD duration, and L-DOPA frequency intake. The global score of parts I, II and III of UPDRS were correlated with the nutritional status. The results confirmed the existence of more severe smell change and taste impairment in the late stage of PD, with more pronounced malnutrition.

Conclusions. The duration of PD, motor and non-motor PD symptoms, and the frequency of L-DOPA intake closely correlate with the nutritional status. Understanding of the multifactorial interdependence might be useful in the estimation of the algorithm for monitoring the nutritional status of PD patients and taking early nutritional intervention.

Key words: malnutrition, Parkinson's disease, Nutrition Risk Screening, Unified Parkinson's Disease Rating Scale, skin fold thickness 


\section{Introduction}

Parkinson's disease (PD) has the $2^{\text {nd }}$ highest incidence rate, after Alzheimer's disease, for neurodegenerative disorders in the population above 50 years of age. Parkinson's disease occurs in about $1 \%$ of the population above 65 years of age. ${ }^{1}$ Malnutrition is an essential problem in the late stage of PD. Lowering of body mass is seen in $30 \%$ of patients, and malnutrition or the risk of malnutrition in $24 \%$ and $60 \%$, respectively. ${ }^{1}$ Malnutrition could be caused by lowering of food intake, motor dysfunctions, motor side effects of treatment (choreatic dyskinesia), dysphagia, or dysautonomia (gastroparesis, constipation). ${ }^{2}$ Cognitive dysfunction, depression and/or a lack of family attention could exacerbate malnutrition in PD patients. Dietary protein manipulation, burning mouth syndrome, removable dentures in oral dyskinesia, and side effects of antiparkinsonian drugs (nausea, vomiting and xerostomia) could influence the nutritional status. Autonomic disturbance, e.g., dysfunction of the subthalamic region responsible for body mass control, is thought to be an important factor in the etiology of PD malnutrition. Other coexisting diseases must be considered in the analysis of malnutrition risk factors. ${ }^{2-5}$

The aim of the study was the analysis of the relationships between the parameters of the nutritional status and the advancement of clinical symptoms in PD patients.

\section{Material and methods}

All patients gave informed written consent to participate in the study. The study was approved by the local Bioethics Committee at Wroclaw Medical University (Poland).

Forty patients with a diagnosis of PD according to the Movement Disorder Society (MDS) clinical criteria from 2015 were analyzed. ${ }^{6}$ There were 18 men and 22 women in the study group, mean age: 70.7 years. Five patients were professionally active, 35 were retired and all of them lived in a city having above 650,000 habitants. All of them were analyzed in an outpatient clinic. All examinations were conducted by clinical nutrition specialists and blinded neurologists specializing in extrapyramidal disorders. In all patients, structured anamnesis was performed: age, sex, disease duration, PD pharmacological therapy, disturbances of smell, taste and gastrointestinal tract, other disorders and their treatment, and addiction to stimulants. The risk of malnutrition was established based on the Nutrition Risk Screening (NRS 2002) and body mass index (BMI). ${ }^{7}$ In NRS 2002 , results $\geq 3$ indicate the threat of malnutrition and the necessity for nutritional intervention. The thickness of 3 skin folds was measured: deltoid, abdominal, and subscapular. The neurological status was based on the Unified Parkinson's Disease Rating Scale (UPDRS, v. 1987; at the time of the study the new version, MDS-UPDRS, had not yet received official approval in Poland), ${ }^{8}$ Schwab and England Activities of Daily Living Scale (SEADLS), ${ }^{9}$ Hoehn-Yahr Standing Scale (H-YSS), ${ }^{10}$ and Beck Depression Scale (BDS) ${ }^{11}$
Each of the points of UPDRS, the collective results of parts I, II and III of UPDRS, and the global result of UPDRS were compared with the parameters of the nutritional status. Blood samples with an estimation of morphology, urea, creatinine, electrolytes (sodium - Na, potassium $-\mathrm{K}$, calcium $-\mathrm{Ca}$ ), magnesium - Mg, and phosphorus - P), liver enzyme activity, as well as lipids, global protein and vitamin D levels were analyzed.

For pairs of parameters, we analyzed the correlation with an estimation of the Pearson's or Spearman's correlation coefficient. A p-value $\leq 0.05$ was considered significant. We used the statistical software program EPIINFO 7.1.1.14 (CDC, Atlanta, USA).

\section{Results}

\section{Nutrition Risk Screening 2002 correlations}

In 10 (25\%) PD patients, the result of NRS 2002 was $\geq 3$ points. The results of NRS 2002 positively correlated with PD duration, while taste disturbances correlated negatively with BMI. A positive correlation was also seen between NRS 2002 result and the frequency of L-DOPA intake, while there was no such correlation between BMI and the frequency of L-DOPA intake (Tables 1, 2).

Table 1. Correlations between the nutritional parameters and the results of SEADLS and H-YSS

\begin{tabular}{|l|c|r|l|}
\multicolumn{1}{|c|}{ Parameter I } & Parameter II & $r$ & p-value \\
\hline Abdominal fold* & SEADLS & 0.43 & 0.017 \\
\hline Smell** & SEADLS & -0.34 & 0.0441 \\
\hline Abdominal fold** & H-YSS & -0.56 & 0.00122 \\
\hline Subscapular fold** & H-YSS & -0.40 & 0.0276 \\
\hline Frequency of L-DOPA intake* & NRS 2002 & 0.41 & 0.012 \\
\hline
\end{tabular}

UPDRS - Unified Parkinson's Disease Rating Scale; H-YSS - Hoehn and Yahr Standing Scale; SEADLS - Schwab and England Activities of Daily Living Scale (Parkinson's Disease); NRS 2002 - Nutritional Risk Screening 2002;

* Pearson's correlation; ** Spearman's correlation.

Table 2. Correlations between the nutritional parameters and the global results of UPDRS, and with parts I, II and III separately

\begin{tabular}{|l|l|r|l|}
\hline \multicolumn{1}{|c|}{ Parameter I } & \multicolumn{1}{|c|}{ Parameter II } & \multicolumn{1}{c|}{$r$} & p-value \\
\hline Abdominal fold* & part I score of UPDRS & -0.36 & 0.040 \\
\hline Smell** & part I score of UPDRS & 0.34 & 0.0442 \\
\hline Abdominal fold* & part II score of UPDRS & -0.46 & 0.010 \\
\hline Subscapular fold* & part II score of UPDRS & -0.42 & 0.019 \\
\hline BMI* & part III score of UPDRS & -0.39 & 0.020 \\
\hline Abdominal fold* & part III score of UPDRS & -0.37 & 0.044 \\
\hline Subscapular fold* & part III score of UPDRS & -0.37 & 0.041 \\
\hline NRS 2002** & part III score of UPDRS & 0.35 & 0.0336 \\
\hline Abdominal fold* & global score of UPDRS & -0.49 & 0.006 \\
\hline Subscapular fold* & global score of UPDRS & -0.41 & 0.022 \\
\hline
\end{tabular}

NRS 2002 - Nutritional Risk Screening 2002; UPDRS - Unified Parkinson's Disease Rating Scale; BMI - body mass index; * Pearson's correlation; ** Spearman's correlation. 


\section{Correlations of other parameters of the nutritional stage}

We revealed a negative correlation between the thickness of the subscapular fold and PD duration, and between the thickness of the abdominal and subscapular folds and the results of H-YSS. The SEADLS scores positively correlated only with the thickness of the abdominal fold (Tables 1, 2).

\section{Smell and taste correlations}

We found a positive tendency, though not statistically significant, between disturbances in smell and taste, and $\mathrm{H}-\mathrm{YSS}$ results. A negative correlation was observed between disturbances in smell and SEADLS score (Tables 2, 3, Fig. 1).

\section{Unified Parkinson's Disease Rating Scale and the nutritional status correlations}

In our study, negative correlations were seen between the collective result of part I of UPDRS and the thickness of the abdominal fold, as well as the collective results of parts I and III of UPDRS and the thickness of the abdominal and subscapular folds. The collective result of part III of UPDRS, the global UPDRS score and BMI negatively correlated with the thickness of the abdominal and subscapular folds. Point 3 (describing depression) and 4 (describing motivation and initiative) of UPDRS negatively correlated with BMI, and the thickness of the abdominal and subscapular folds. Paradoxically, the results from BDS did not correlate with NRS 2002 score, BMI or the thickness of the skin folds. Point 3 positively correlated with part III of UPDRS and with NRS 2002 score. The following points negatively correlated with the thickness of the skin folds: 9 (cutting food, handling utensils) with the abdominal fold, 14 (freezing when walking) with the abdominal and subscapular folds, 24 (bilateral hand movements) with the subscapular fold, and 29 (gait) and 30 (postural stability) with the abdominal fold. Positive correlations were noted for point 40 of UPDRS (anorexia, nausea, vomiting) and the thickness of the deltoid, abdominal and subscapular folds, and with BMI. We revealed positive correlations between NRS 2002 score and UPDRS points: 14 (freezing when walking), 28 (posture), 31 (body bradykinesia and hypokinesia), 32 (duration: in what proportion of the walking day are dyskinesias present?), and 33 (disability: how disabling are dyskinesias?).

Disturbances in smell positively correlated with points 9 (cutting food, handling utensils) and 20 (tremor at rest for the right upper limb), as well as the collective result of part I of UPDRS. Taste disturbances positively correlated with point 23 (finger taps for the right upper limb) of UPDRS. The level of vitamin D positively correlated with point 17 of UPDRS (sensory complaints related to parkinsonism). The correlations described above are shown in Tables 1-3.

\section{Discussion}

The study showed a lot of correlations between the severity of PD, mostly motor symptoms in UPDRS, and parameters characterizing the patient's nutritional status. In $25 \%$ of PD patients, we revealed the threat of malnutrition or undernutrition. Wang et al. presented similar results in PD patients in a Chinese population (22.9\%) and Barichella et al. in an Italian patient group (20\%). ${ }^{12,13}$ In the Chinese group, malnutrition was seen in $2 \%$ of PD patients. In previous studies, detailed correlations between consequent clinical symptoms in UPDRS and nutritional status parameters were not analyzed. The authors focused only on a comparison between the nutritional parameters and

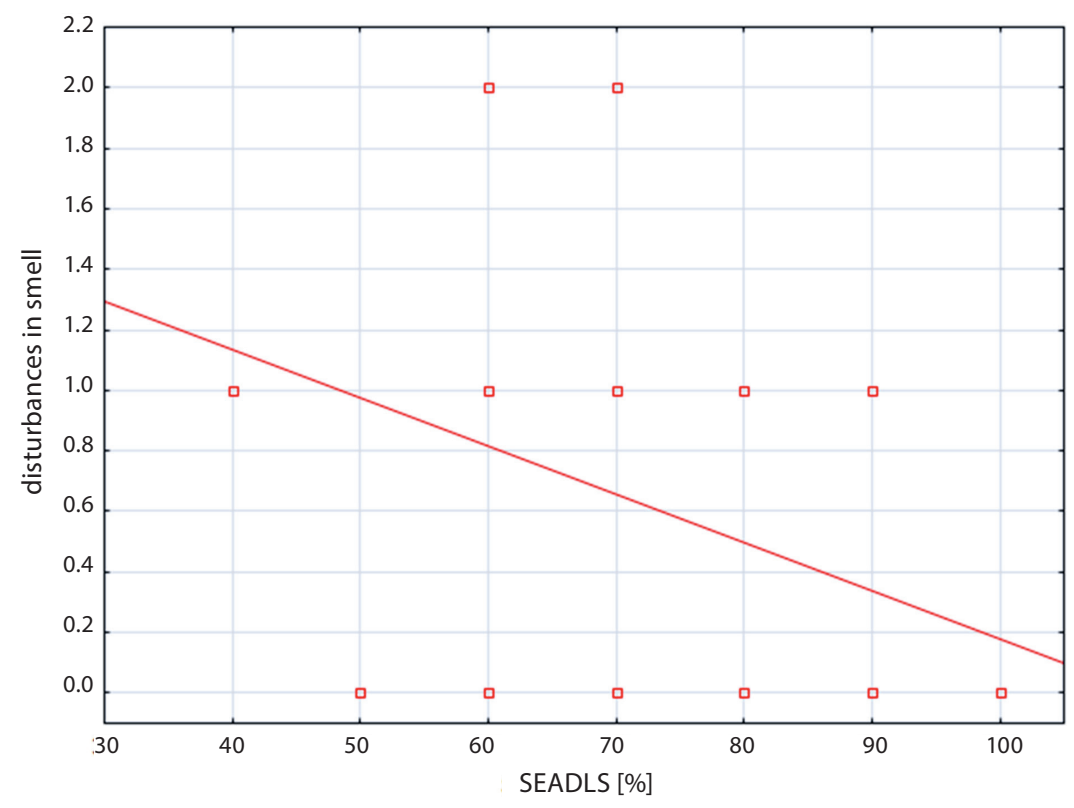

Fig. 1. A negative correlation observed between disturbances in smell and Schwab and England Activities of Daily Living Scale (SEADLS) 
Table 3. Correlations between the nutritional parameters and the results of the respective points of UPDRS

\begin{tabular}{|c|c|c|c|}
\hline Parameter I & Parameter II & $r$ & $p$-value \\
\hline $\begin{array}{l}\text { Point } 3 \text { of UPDRS } \\
\text { (depression)* }\end{array}$ & $\mathrm{BMI}$ & -0.37 & 0.0288 \\
\hline $\begin{array}{l}\text { Point } 3 \text { of UPDRS } \\
\text { (depression)* }^{*}\end{array}$ & abdominal fold & -0.36 & 0.0495 \\
\hline $\begin{array}{l}\text { Point } 3 \text { of UPDRS } \\
\text { (depression) }^{*}\end{array}$ & subscapular fold & -0.46 & 0.00844 \\
\hline $\begin{array}{l}\text { Point } 4 \text { of UPDRS } \\
\text { (motivation/initiative) }^{*}\end{array}$ & $\mathrm{BMI}$ & -0.35 & 0.0413 \\
\hline $\begin{array}{l}\text { Point } 4 \text { of UPDRS } \\
\text { (motivation/initiative) }^{*}\end{array}$ & abdominal fold & -0.49 & 0.00623 \\
\hline $\begin{array}{l}\text { Point } 9 \text { of UPDRS } \\
\text { (cutting food and handling utensils)* }\end{array}$ & abdominal fold & -0.37 & 0.0414 \\
\hline $\begin{array}{l}\text { Point } 9 \text { of UPDRS } \\
\text { (cutting food and handling utensils)* }\end{array}$ & smell & 0.37 & 0.0266 \\
\hline $\begin{array}{l}\text { Point } 14 \text { of UPDRS } \\
\text { (freezing when walking)* }\end{array}$ & deltoid fold & -0.41 & 0.0237 \\
\hline $\begin{array}{l}\text { Point } 14 \text { of UPDRS } \\
\text { (freezing when walking)* }\end{array}$ & abdominal fold & -0.46 & 0.00978 \\
\hline $\begin{array}{l}\text { Point } 17 \text { of UPDRS } \\
\text { (sensory complaints related to parkinsonism)** }\end{array}$ & vitamin D & -0.35 & 0.0406 \\
\hline $\begin{array}{l}\text { Point } 20 \text { of UPDRS } \\
\text { LLR (tremor at rest)** }\end{array}$ & vitamin D & 0.35 & 0.0449 \\
\hline $\begin{array}{l}\text { point } 21 \text { of UPDRS } \\
\text { LLL (action or postural tremor of hands)* }\end{array}$ & deltoid fold & -0.36 & 0.0467 \\
\hline $\begin{array}{l}\text { Point } 23 \text { of UPDRS } \\
L \text { (finger taps)* }\end{array}$ & abdominal fold & -0.51 & 0.00375 \\
\hline $\begin{array}{l}\text { Point } 23 \text { of UPDRS } \\
L \text { (finger taps)* }^{*}\end{array}$ & subscapular fold & -0.45 & 0.0116 \\
\hline $\begin{array}{l}\text { Point } 24 \text { of UPDRS } \\
\text { R (hand movements)* }\end{array}$ & subscapular fold & -0.50 & 0.00435 \\
\hline $\begin{array}{l}\text { Point } 24 \text { of UPDRS } \\
L \text { (hand movements)* }\end{array}$ & subscapular fold & -0.37 & 0.0400 \\
\hline $\begin{array}{l}\text { Point } 26 \text { of UPDRS } \\
L \text { (leg agility)* }\end{array}$ & $\mathrm{BMI}$ & -0.37 & 0.0310 \\
\hline $\begin{array}{l}\text { Point } 26 \text { of UPDRS } \\
L \text { (leg agility)* }\end{array}$ & abdominal fold & -0.48 & 0.00788 \\
\hline $\begin{array}{l}\text { Point } 29 \text { of UPDRS } \\
\text { (gait)* }\end{array}$ & abdominal fold & -0.38 & 0.0380 \\
\hline $\begin{array}{l}\text { Point } 30 \text { of UPDRS } \\
\text { (postural stability) }\end{array}$ & abdominal fold & -0.41 & 0.0241 \\
\hline $\begin{array}{l}\text { Point } 40 \text { of UPDRS } \\
\text { (anorexia, nausea or vomiting)* }\end{array}$ & BMI & -0.50 & 0.00199 \\
\hline $\begin{array}{l}\text { Point } 40 \text { of UPDRS } \\
\text { (anorexia, nausea or vomiting)* }\end{array}$ & deltoid fold & -0.43 & 0.0159 \\
\hline $\begin{array}{l}\text { Point } 40 \text { of UPDRS } \\
\text { (anorexia, nausea or vomiting)* }\end{array}$ & abdominal fold & -0.54 & 0.00197 \\
\hline $\begin{array}{l}\text { Point } 40 \text { of UPDRS } \\
\text { (anorexia, nausea or vomiting)* }\end{array}$ & subscapular fold & -0.55 & 0.00145 \\
\hline
\end{tabular}

UPDRS - Unified Parkinson's Disease Rating Scale; ULR - upper limb right; LLL - lower limb left; LLR - lower limb right; L - left; R - right; BMI - body mass index; ${ }^{*}$ Spearman's correlation.

the global score of parts I, II or III of UPDRS. Only the BMI results or unintended weight loss were considered the basic criteria of the nutritional status. There was no analysis of the skin fold thickness. Body mass index seems to be a rather limited parameter, because it relates only to body mass and not to the nutritional status, and it gives false results in some groups of patients (asthenic, very tall or very short), or in patients with posture changes resulting from the reductions in height. ${ }^{14,15}$ Such a situation can cause BMI augmentation. In our study, a negative correlation 
was seen between BMI and part III of UPDRS. Sheard et al. compared the Subjective Global Assessment (SGA) with the global score of UPDRS and showed a positive correlation between these parameters. ${ }^{16}$ Fereshtehnejad et al. disputed these results, as they did not find any statistical differences in terms of malnutrition when comparing a large population of Iranian PD patients with healthy people. ${ }^{17}$ Barichella et al. analyzed the clinical stage of PD patients with malnutrition in each part of UPDRS. ${ }^{2}$ They revealed lower body mass and BMI in the patient group. The authors did not correlate the results of the executive parts of UPDRS with the nutritional status.

The most important correlation was seen between the risk of malnutrition in NRS 2002 and the duration of PD. These results were compatible with the findings of Jaafar et al. ${ }^{18}$ Most of the previous studies indicated the loss of body mass with the rising severity of the disease. ${ }^{4,12,19}$

Our very interesting observation was the influence of the frequency of L-DOPA intake on the nutritional status. We revealed a greater risk of malnutrition in patients whotook L-DOPA more frequently. We did not find any correlation between L-DOPA intake frequency and BMI. Sheard et al. and Fereshtehnejad et al. also did not show any relationship between the L-DOPA global dose and the nutritional status. ${ }^{16,17}$ The dependence of the nutritional status and the risk of malnutrition in PD patients on the frequency of L-DOPA intake could be connected with the reduction of the amount of food intake, mainly proteinaceous. The reduction of food intake in order to improve L-DOPA absorption and high energy cost in the course of choreatic dyskinesia are important risk factors for malnutrition. Nausea, as a side effect of L-DOPA treatment, can also cause the reduction of food intake.

According to a theory presented by Braak et al., smell changes could be the $1^{\text {st }}$ symptoms of PD. ${ }^{20}$ In our patients, we revealed a negative correlation between these smell changes and SEADLS score. These results confirmed the existence of more severe smell changes in the late stage of $\mathrm{PD}$, with more pronounced malnutrition. A positive correlation was seen between smell changes and the global score of part I of UPDRS, e.g., the intellectual status, mood and behavior. Taste impairment positively correlated with the results of NRS 2002. In the available literature, no one describes the influence of taste impairment on the risk of malnutrition. ${ }^{3,12,13,15,19}$

The estimation of skin fold thickness is a very important parameter in the analysis of malnutrition. According to our findings using UPDRS and H-YSS, skin fold thickness depends on PD duration and the grade of progression. Abdominal fold thickness seems to be the best parameter, which correlates with all used scales. The problems of self-feeding and alternative limb movements, and the occurrence of freezing (points 14, 23, 24, and 26 of UPDRS) negatively influence skin fold thickness. Parkinson's disease patients fed by their caregivers had smaller skin folds than PD patients with preserved self-feeding ability.
We also revealed the negative influence of depression, as well as motivation and initiative disturbances (point 3 and 4 of UPDRS) on BMI and skin fold thickness. Our results are compatible with those presented in the study by Fereshtehnejad et al. ${ }^{21}$ Emotional disturbances influence the nutritional status, and the early recognition of these allows for preventative steps to be taken, as well as early treatment.

In the late stage of $\mathrm{PD}$, the frequency of falls is greater. We observed a negative correlation between the thickness of the abdominal fold and postural stability. The enhancement of sensory complaints (point 17 of the UPDRS) and lowering of vitamin D level could be important factors for the risk of falling. The prevention of malnutrition with vitamin D supplementation could diminish the risk of falling and its complications, e.g., bone fractures.

\section{Conclusions}

The duration of PD, motor and non-motor PD symptoms, and the frequency L-DOPA intake closely correlate with the nutritional status. Understanding of the multifactorial interdependence might be useful in the estimation of an algorithm for monitoring the nutritional status of PD patients and early nutritional intervention.

\section{References}

1. World Health Organization. Neurological Disorders. Public Health Challenges. Geneva, Switzerland: WHO Press; 2007.

2. Barichella M, Cereda E, Cassani E, et al. Dietary habits and neurological features of Parkinson's disease patients: Implications for practice. Clin Nutr. 2016;36(4):1054-1061. doi: 10.1016/j.clnu.2016.06.020

3. Lindskov S, Sjöberg K, Hagell P, Westergren A. Weight stability in Parkinson's disease. Nutr Neurosci. 2016;19(1):11-20.

4. Bachmann CG, Trenkwalder C. Body weight in patients with Parkinson's disease. Mov Disord. 2006;21(11):1824-1830.

5. Lindskov S, Sjöberg K, Westergren A, Hagell P. Malnutrition risk in Parkinson's disease. J Aging Res Clin Pract. 2014;3:93-99.

6. Postuma RB, Berg D, Stern M, et al. MDS clinical diagnostic criteria for Parkinson's disease. Mov Disord. 2015;30(12):1591-1601.

7. Kondrup J, Rasmussen H, Hamberg O, Stanga Z; Ad Hoc ESPEN Working Group. Nutritional Risk Screening (NRS 2002): A new method based on an analysis of controlled clinical trials. Clin Nutr. 2003;22(3): 321-336.

8. Fahn S, Elton R; Members of the UPDRS Development Committee. Unified Parkinson's Disease Rating Scale. In: Fahn S, Marsden CD, Calne DB, Goldstein M, eds. Recent Developments in Parkinson's Disease, Vol 2. Florham Park, NJ: Macmillan Health Care Information; 1987;153-163, 293-304.

9. Schwab RS, England AC. Projection technique for evaluating surgery in Parkinson's disease In: Gillingham FJ, Donaldson MC, eds. Third Symposium on Parkinson's Disease. Edinburgh, UK: E\&S Livingston; 1969:152-157.

10. Hoehn M, Yahr M. Parkinsonism: Onset, progression and mortality. Neurology. 1967;17(5):427-442.

11. Beck AT. Depression: Causes and Treatment. Philadelphia, PA: University of Pennsylvania Press; 1972.

12. Wang G, Wan Y, Cheng Q, et al. Malnutrition and associated factors in Chinese patients with Parkinson's disease: Results from a pilot investigation. Parkinsonism Relat Disord.2010;16(2):119-123.

13. Barichella M, Villa MC, Massarotto A, et al. Nutritional assessment in patients with Parkinson's disease: Correlation between worsening of the malnutrition and increasing number of disease-years. Nutr Neurosci. 2008;11(3):128-134. 
14. Cheshire WP Jr, Wszolek ZK. Body mass index is reduced early in Parkinson's disease. Parkinsonism Relat Disord. 2005;11(1):35-38.

15. van der Marck MA, Dicke HC, Uc EY, et al. Body mass index in Parkinson's disease: A meta-analysis. Parkinsonism Relat Disord. 2012;18(3): 263-267.

16. Sheard JM, Ash S, Mellick GD, Silburn PA, Kerr GK. Markers of disease severity are associated with malnutrition in Parkinson's disease. PLoS One. 2013;8(3):e57986.

17. Fereshtehnejad SM, Ghazi L, Sadeghi M, et al. Prevalence of malnutrition in patients with Parkinson's disease: A comparative study with healthy controls using Mini Nutritional Assessment (MNA) questionnaire. J Parkinsons Dis. 2014;4(3):473-481.
18. Jaafar AF, Gray WK, Porter B, Turnbull EJ, Walker RW. A cross-sectional study of the nutritional status of community-dwelling people with idiopathic Parkinson's disease. BMC Neurol. 2010;10:124. doi: 10.1186/1471-2377-10-124

19. Kashihara K. Weight loss in Parkinson's disease. J Neurol. 2006;253 (Suppl 7):38-41.

20. Braak H, Del Tredici K, Rüb U, de Vos RA, Jansen Steur EN, Braak E. Staging of brain pathology related to sporadic Parkinson's disease. Neurobiol Aging. 2003;24(2):197-211.

21. Fereshtehnejad SM, Ghazi L, Shafieesabet M, Shahidi GA, Delbari A, Lökk J. Psychiatric and fatigue features associated with nutritional status and its effects on quality of life in Parkinson's disease patients. PLoS One. 2014;9(3):e91153. 